\title{
Prevalence of Toxoplasma gondii Antibodies in Stray Dogs from Various Locations in West and East Malaysia
}

\author{
Malaika Watanabe ${ }^{1}$, Mohammed Babatunde Sadiq ${ }^{2}$, Nazrul Iqbal Abdul Mulop ${ }^{3}$, Konto Mohammed ${ }^{6}$, \\ Puteri Azaziah Megat Rani', Lau Seng Fong ${ }^{3}$, Nor Azlina Aziz ${ }^{4}$ (0), Juriah Kamaludeen ${ }^{5}$, Siti Zubaidah Ramanoon², \\ Rozaihan Mansor', Tan Li Ping', Sharifah Salmah Syed-Hussain,"* (i) \\ ${ }^{1}$ Department of Companion Animal Medicine and Surgery, ${ }^{2}$ Department of Farm and Exotic Animal Medicine and Surgery, ${ }^{3}$ Department of Veterinary \\ Clinical Studies, ${ }^{4}$ Department of Veterinary Pathology and Microbiology, Faculty of Veterinary Medicine, Universiti Putra Malaysia, 43400 UPM \\ Serdang, Selangor, Malaysia; ${ }^{5}$ Department of Animal Science and Fisheries, Faculty of Agriculture and Food Science, Universiti Putra Malaysia \\ Bintulu, Sarawak Campus, P.O Box 396, Nyabau Road, 97008 Bintulu, Sarawak, Malaysia; ${ }^{6}$ Department of Veterinary Parasitology and Entomology, \\ University of Maiduguri, Nigeria, P.M.B. 1069, Bama Road, Maiduguri, Borno State, Nigeria
}

\begin{abstract}
Toxoplasmosis is caused by an obligate intracellular protozoan parasite; Toxoplasma gondii, which is one of the most important zoonotic parasite worldwide. In dogs, the sexual reproductive cycle of $T$. gondii is lacking, and the animals are not widely consumed as food, but they are vital in the mechanical transmission of the parasite. However, there is no present data on the exposure of stray dogs to T. gondii in Malaysia. The objective of this serological survey was to determine the prevalence of T. gondii antibodies (IgG) and associated factors in stray dogs in East and West Malaysia. Antibodies to T. gondii were determined in serum samples from 222 stray dogs from 6 different states in East and West Malaysia (Peninsular Malaysia) using an Indirect ELISA. The seroprevalence for T. gondii was 23.4\% (Confidence interval: $\mathrm{Cl}$ 17.8-29.2\%). Stray dogs from Selangor and Kuala Lumpur had the highest seroprevalence (32.4\%; Cl 13.2-45.5\%) and lowest in those from Penang and Kedah (12.5\%; Cl 1.3-23.5\%). Gender and breed were not associated with T. gondii seropositivity. However, adult dogs were more likely to be seropositive for $T$. gondii $(\mathrm{OR}=2.89 ; \mathrm{Cl} 1.1-7.7)$ compared with younger dogs. These results revealed that $T$. gondii is prevalent in stray dogs in the studied areas in Malaysia, and indicative of the level of environmental contamination of this parasite especially in urban areas.
\end{abstract}

Key words: T. gondii, stray dog, prevalence, ELISA, Malaysia

\section{INTRODUCTION}

Toxoplasmosis is caused by an obligate intracellular protozoan parasite; Toxoplasma gondii capable of infecting all warmblooded animals including humans, mammals and birds $[1,2]$. Toxoplasmosis is one of the most important zoonotic parasitic diseases worldwide [1,3]. It is considered as one of the most effective parasitic infections with about $1 / 3$ of the human population infected by the pathogen [3]. Although toxoplasmosis appears asymptomatic in most humans, the risks are severe in pregnant women as it may cause severe health implications to the fetus $[1,2]$.

- Received 29 May 2020, revised 15 September 2020, accepted 22 September 2020. *Corresponding author (sharifahsalmah@gmail.com)

(c) 2020, Korean Society for Parasitology and Tropical Medicine

This is an Open Access article distributed under the terms of the Creative Commons Attribution Non-Commercial License (https://creativecommons.org/licenses/by-nc/4.0) which permits unrestricted non-commercial use, distribution, and reproduction in any

medium, provided the original work is properly cited.
Felids are the only definitive host of $T$. gondii with an infected cat capable of discharging millions of infective oocysts in feces for few days post-infection [4]. Humans, rodents and other animals serve as intermediate hosts and become infected through ingestion of oocysts from the environment either by consumption of contaminated food, undercooked meat containing T. gondii tissue cysts, or direct contact with oocysts excreted in cats feces $[5,6]$. While the distribution of the tissue cysts may vary among the intermediate hosts, the ingestion of tissue cysts from undercooked meat remains the major route of infection in humans $[5,6]$.

The sexual reproductive phase of $T$. gondii is lacking in dogs, and the animals are not widely consumed as food, but they could serve as means of mechanical transmission of the parasite $[7,8]$. Dogs infected with T. gondii may not manifest clinical signs; however, they may occasionally show digestive, respiratory, and neurological signs and muscular anomalies, especially in immunocompromised patients [3]. Particularly, the 
risk of transmission of the T. gondii in dogs has been linked to their coprophagic and rolling behavior over grass or feces probably contaminated with oocysts $[9,10]$.

The presence of $T$. gondii oocyst in the environment is an important portal for acquired toxoplasmosis [11]. Information on the environmental burden of T. gondii can be indirectly obtained from data on its seroprevalence in free-living animals. Stray dogs are considered as sentinels for indirect measurement of the burden of T. gondii in the environment, since they often roam about and are in close contact with the contaminated environment inhabited by humans [9]. The similarity in the prevalence of $T$. gondii infection in dogs and humans is also indicative of the former as an adequate sentinel of the parasite [12-14]. In comparison to domestic dogs, there is relatively fewer studies conducted in stray dogs to understand their role in the transmission of T. gondii. Most studies have focused on domestic dogs and cats probably due to their close interaction with humans $[5,6]$.

In Malaysia, previous studies have reported the prevalence of T. gondii in domestic dogs, goats, poultry and wild boar and exotic meats [15-18]. A recent study also reported high seroprevalence of T. gondii (57.4\%; 52.7-61.8\%) among migrant workers in farms and plantations [19]. The increasing urbanization in the main cities may also influence $T$. gondii transmission and distribution in the environment [13]. However, there is no information about $T$. gondii prevalence in stray dogs in any parts of the nation. In view of this background, the objective of this study was to determine the prevalence of $T$. gondii antibodies in stray dogs and to identify the associated risk factors in various states in Malaysia.

\section{MATERIALS AND METHODS}

This study was approved by the Institutional Animal Care and Use Committee University Putra Malaysia (IACUC) (Approval code: R074/2013). Shelters were identified from the directory provided by the Department of Veterinary Services. The management officers in the respective shelters were briefed about the aim of the study and methodology, and those willing to participate were informed about the scheduled sampling dates. Upon visits to the shelters, the sample size was estimated based on the total number of stray dogs in each shelter. A random sample of stray dogs were selected from each shelter until the required sample size was reached. The sampled dogs were from the quarantine units and were newly introduced to the animal shelters. A total of 222 stray dogs were sampled from animal shelters in different states in Malaysia namely Selangor, Johor, Penang/Kedah, Pahang, Sabah and Sarawak, as well as three shelters located in Kuala Lumpur (KL) and Klang valley (Fig. 1).

The dogs were of different sex, age and breed and the sampling was conducted from May 2013 to June 2014. Dogs were categorized as young if within the age of 0 to 18 months, while those above 18 months were considered as adult. The breeds were categorized into pedigree (known breed) and local (no defined breed). Thereafter, the dogs were restrained appropriately and $3 \mathrm{ml}$ of blood was collected via venipuncture into plain tubes and separated for serology. Sera samples were kept in $-20^{\circ} \mathrm{C}$ till further analysis. The sera samples were subjected to a commercially available ELISA test kit (ID Screen ${ }^{\circledR}$ Toxoplasmosis-Indirect Multi-Species Test Kit, France). Briefly, the assay

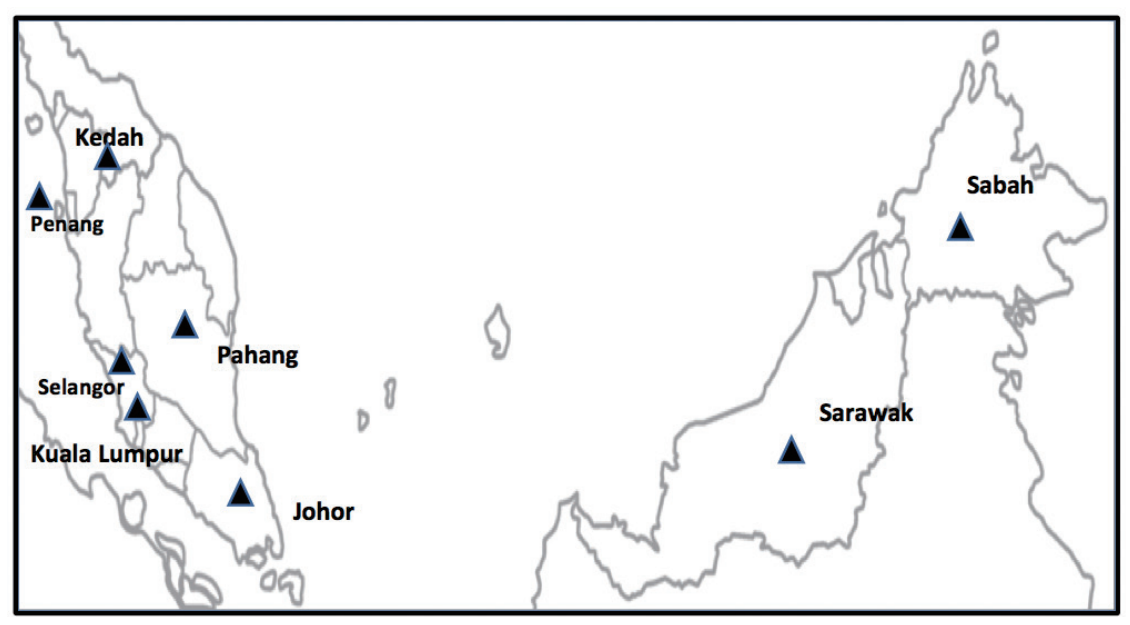

Fig. 1. A map showing serum sampling areas ( $\mathbf{\Lambda}$ ) from stray dogs in East and West Malaysia. 
utilizes T. gondii P30 antigen and anti-multi-specie IgG conjugates, which detects T. gondii antibodies from ruminants, cats, dogs and swine. The sample to positive ratio $(\mathrm{S} / \mathrm{P})$ were calculated for each sample (S/P \%: [OD sample/OD positive control $\times 100]$ ). As recommended by the manufacturer, samples with $\mathrm{S} / \mathrm{P}$ of $\geq 50 \%$ were considered positive, $\mathrm{S} / \mathrm{P}$ of 40 to $\leq 50 \%$ as doubtful and $\mathrm{S} / \mathrm{P} \leq 40 \%$ as negative. Samples with doubtful results were considered as negative in this study.

Data were analyzed using SPSS Version 25 (IBM, Armonk, New York, USA). Descriptive statistics were applied to summarize the data and to determine the seroprevalence of $T$. gondii in the studied population. Binary logistic regression models were applied to determine the factors associated with T. gondii seroprevalence. At univariable level, each factor was tested with the dependent variable, and $P<0.1$ was considered for any factor to be introduced into the next model. At multivariate level, $P<0.05$ was considered for any significant relationship, while odds ratio (OR) and 95\% confidence interval (CI) were used to express the strength of the association.

\section{RESULTS}

Table 1 shows the characteristics of the study population and the corresponding seroprevalence. The proportion of female and male stray dogs was $52.3 \%$ and $47.3 \%$ respectively. Twenty percent of them were classified as young (0-18 months), whereas

Table 1. Seroprevalence of Toxoplasma gondii antibodies in stray dogs from various locations in East and West Malaysia

\begin{tabular}{lrrcc}
\hline Factors & Frequency & $\%$ & Seroprevalence & $\%$ \\
\hline Gender & & & & \\
Male & 106 & 47.7 & 22 & 20.8 \\
Female & 116 & 52.3 & 30 & 25.9 \\
Age & & & & \\
Young & 45 & 20.3 & 5 & 11.1 \\
Adults & 177 & 79.7 & 47 & 26.6 \\
Breed & & & & \\
Pedigree & 37 & 16.7 & 8 & 21.6 \\
Local & 185 & 83.3 & 44 & 23.8 \\
Location & & & & \\
KL/Selangor & 34 & 15.3 & 11 & 32.4 \\
Johor & 37 & 16.7 & 9 & 24.3 \\
Pinang and Kedah & 40 & 18 & 5 & 12.5 \\
Pahang & 37 & 16.7 & 8 & 21.6 \\
Sabah & 37 & 16.7 & 11 & 29.7 \\
Sarawak & 37 & 16.7 & 9 & 24.3 \\
Total & 222 & 100 & 52 & 23.4 \\
\hline
\end{tabular}

Cl: confidence interval.
$80 \%$ were above 18-month-old (adults). Majority of the dogs were local breeds (83.3\%) compared to those of specific breed type (16.7\%). The number of sampled animals from each sampling site ranged from 34 to 40 dogs (Table 2). Among the 222 animals, 52 (23.4\%; CI 17.8-29.2\%) were found to be seropositive for $T$. gondii antibodies. The highest seroprevalence was observed in KL/Selangor (32.4\%; 11/34), followed by Sabah $(9 / 37 ; 24.3 \%)$, and lowest in Penang and Kedah $(5 / 40$; $12.5 \%)$.

The association between the animal-based factors (breeds, age, and sex), location, and T. gondii seroprevalence is presented in Table 2. At Univariable level, only the age of the animals was associated with the outcome, as adult dogs were 2 times more likely to be seropositive for $T$. gondii $(\mathrm{OR}=2.8$; 95\% 1.17.7) compared to young dogs. The seroprevalence between male and female stray dogs were $20.8 \%$ and $25.9 \%$ respectively, but gender was not associated with $T$. gondii seroprevalence $(P=0.37)$. Likewise, breed and location were not associated with prevalence of $T$. gondii antibodies. However, marked difference in the seroprevalence estimates was observed between KL/Selangor (32.4\%) and Pinang/Kedah (12.5\%). At multivariable level, adult dogs were more likely to be seropositive $(\mathrm{OR}=2.89 ; \mathrm{CI} 1.07-7.7)$ compared with the young group.

\section{DISCUSSION}

This study is the first to report the seroprevalence of $T$. gondii among stray dogs in Malaysia. T. gondii antibodies were detected in $23 \%$ of the stray dogs examined, which may be a pointer of high oocyst environmental contamination in the studied locations. Humid tropical climates are conducive for the maintenance of soils and water where T. gondii oocysts are widely distributed [20]. This similar climatic condition in Malaysia coupled with the interaction between domestic and wild animals could contribute to the maintenance of transmission oocysts of the parasite. The seroprevalence rate in this study (23\%) is higher than the one reported in pet dogs in Peninsular Malaysia $(9.6 \%)$ by Chandrawathani et al. [15]. One possible reason for the high prevalence in stray dogs is the ingestion of food thrown in garbage cans and rubbish on the streets. Stray dogs are more exposed to T. gondii oocysts compared to owned dogs $[33,38]$. Moreover, stray dogs were observed roaming the streets, public places, and open markets in areas not too far from the sampled shelters.

Different serological techniques are used to detect T. gondii 
Table 2. Analytics on association of Toxoplasma gondii infection factors in stray dogs in East and West Malaysia

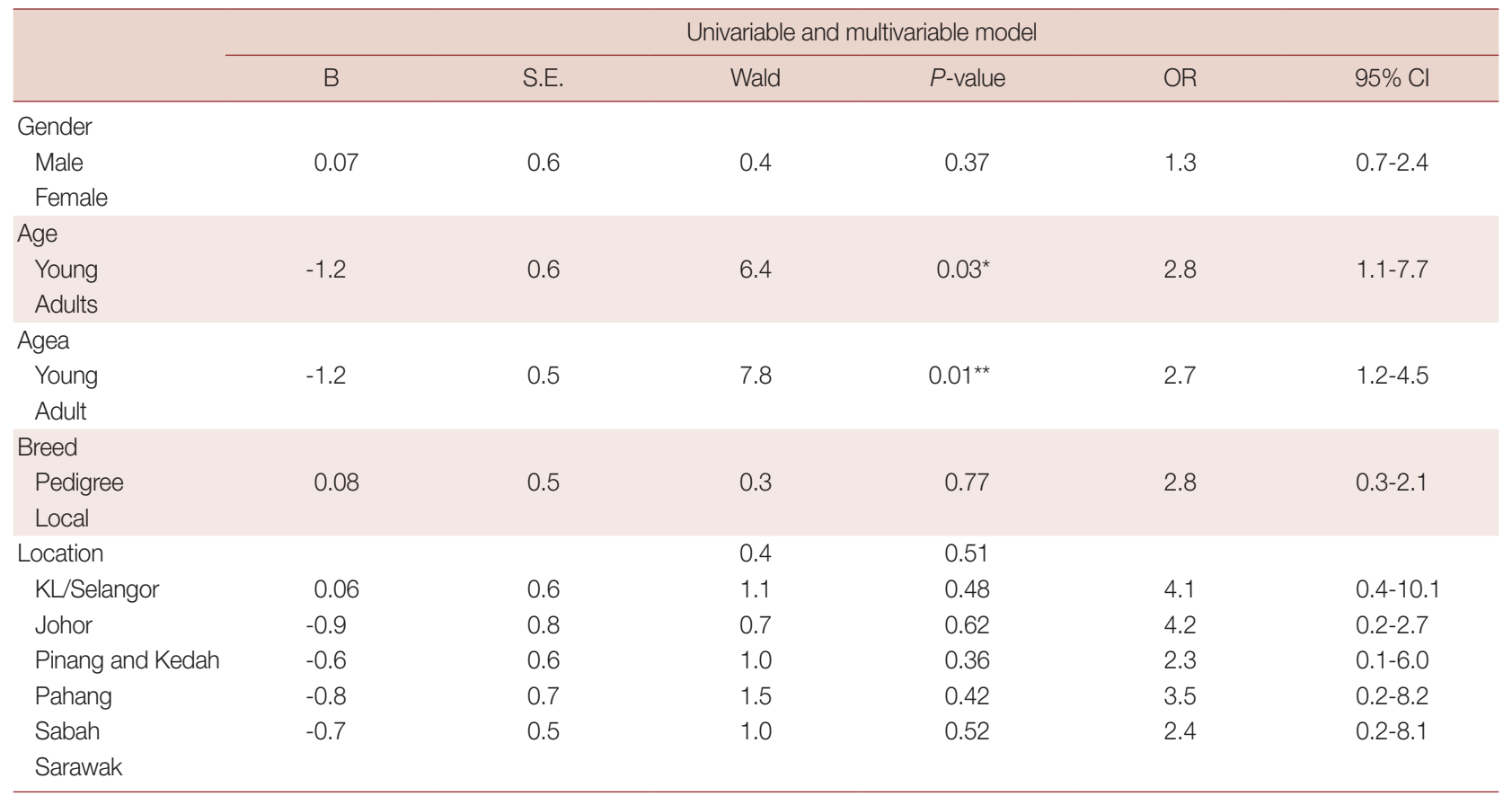

Cl, confidence interval; OR, odds ratio; S.E, standard error.

"Multivariable model for the factor "age".

*Significant at univariable model $(P<0.1)$.

${ }^{*}$ Significant at multivariable model $(P<0.05)$.

antibodies in dogs. This include modified agglutination test [21,22], latex agglutination test [23], indirect fluorescence antibody test [24] and ELISA [14]. In this study, ELISA was applied for detecting antibodies for T. gondii. Several researchers have used ELISA and few studies comparing the efficacy between various serological methods supported the use of ELISA for $T$. gondii antibodies detection $[25,26]$. The wide application of ELISA for epidemiological investigation of toxoplasmosis is due to its high sensitivity, cost-effectiveness, and practicality $[2,5]$. In addition, immunoglobulin G; IgG antibodies for $T$. gondii were assessed in the present study. This is supported by the fact that upon T. gondii infection, $\operatorname{IgG}$ antibodies often appears within the first or second week and reach a peak after a month [5]. Moreover, the assay used to identify the antibodies has a specificity and sensitivity of $98 \%$ and $95 \%$, respectively [26]. In comparison to other studies where related immunodiagnostic method was applied, our result is similar to the seroprevalence reported among stray dogs in Czech Republic (25.9\%) [27] and Turkey (19.8\%) [28], lower compared to results from China (51.9\%) [29], Brazil (70.9\%) [30], Sri Lanka (67.4\%) [31], and Portugal (38.0\%) [32], but higher than results among stray dogs in Philippines (15.2\%) [33] and Northwest- ern China (14.5\%) [34]. Differences in the prevalence estimates in different regions result from the predominance of factors influencing exposure to the parasite. Specifically, comparison between these studies suggest that climatic conditions in various countries could influence T. gondii seroprevalence, with moist and warmer locations recording higher prevalence rates [5].

Based on the data analysis by location, results showed no significant difference in the frequency of $T$. gondii. However, $32.5 \%$ of the samples from KL/Selangor were seropositive compared to those from Penang/Kedah (12.5\%). The seroprevalence rates in most of the locations suggest that similar factors may be influencing the exposure of stray dogs to T. gondii infection [35]. Nevertheless, the location-KL/Selangor with highest seroprevalence is relatively more urbanized and densely populated, which may increase the exposure of stray dogs to environment contaminated with oocysts. Saldanha-Elias et al. [36] reported that stray dogs from urban areas had higher risk of $T$. gondii seropositivity compared to those from rural areas. Specific factors common in urban areas such as high population of cats, human-related activities leading to more garbage cans in the street, and exposure to poorly cooked meat may 
heighten the risk of $T$. gondii infection in stray dogs [35]. Additionally, shelters in the sampled areas with high seroprevalence might have cats that readily interact with the quarantined dogs or share a common environment. Although, we did not assess the population of cats in the shelters, the role of cats in the transmission of this parasite in the sampling area is equally important. Other likely reasons for the high seroprevalence include: 1) the availability of preys such as rodents for stray dogs to hunt; 2) garbage consumption as majority of the dogs examined from the shelters were rescued from roads where they were exposed to contaminated garbage, infected small mammals and birds; 3 ) feeding on water and leftover food contaminated with T. gondii oocysts.

The present study showed that seroprevalence of $T$. gondii was not associated with breed and gender. This is similar to the findings of Yan et al. [14] in which no associations were observed in seroprevalence between various breeds of stray dogs. Also, the gender of stray and owned dogs was not associated with $T$. gondii infection in other studies [21,37]. This finding might be linked to the absence of marked behavioral difference between male and female stray dogs, which may influence exposure to the parasite [38]. There was a significant association between age and T. gondii seroprevalence, as adults were more likely to be infected compared with young dogs. This corroborates the results of Yan et al. [14] and Lopes et al. [21] where the levels of T. gondii antibody increased with age. Adult dogs are more likely to be exposed to $T$. gondii oocysts as they have greater roaming behavior and may come in contact with environment, garbage and leftover foods contaminated by the parasite.

This is the first report of $T$. gondii antibodies detected in stray dogs in Malaysia. The present result suggests high exposure of stray dogs to the parasite in East and West Malaysia. Adult stray dogs and those from high urban areas such as KL and Selangor had the higher risk of exposure to T. gondii. The high prevalence of T. gondii infection in stray dogs reflects the magnitude of the parasite contamination in the environment, and the need for preventive measures against their potential role in mechanical transmission of the parasite.

\section{ACKNOWLEDGMENT}

The authors would like to thank Universiti Putra Malaysia for funding the present work through the Inisiatif Putra Muda grant scheme (GP-IPM/2016/9509800) and the Research Uni- versity grant scheme (01-01-09-0662RU).

\section{CONFLICT OF INTEREST}

The authors declare that they have no conflicts of interest.

\section{REFERENCES}

1. Dubey JP. Toxoplasmosis of Animals and Humans. Boca Raton, USA. CRC press. 2016.

2. Shapiro K, Bahia-Oliveira L, Dixon B, Dumètre A, de Wit LA, VanWormer E, Villena I. Environmental transmission of Toxoplasma gondii: oocysts in water, soil and food. Food and Waterborne Parasitol 2019; 15: e00049.

3. Calero-Bernal R, Gennari S. Clinical toxoplasmosis in dogs and cats: an update. Front Vet Sci 2019; 6: 54.

4. Ma MJ, Tan G, Jiang X, OuYang Y. The epidemiology and prevention and control of toxoplasmosis in dogs and cats. Hubei Anim Husb Vet 2012: 25-26.

5. Dubey JP, Tiao N, Gebreyes WA, Jones JL. A review of toxoplasmosis in humans and animals in Ethiopia. Epidemiol Infect 2012; 140: 1935-1938.

6. Li B, Zhong N, Peng W, Shang L, Jin H, Liu Q. Seroprevalence of Toxoplasma gondii infection in dogs in Sichuan Province, southwestern China. J Parasitol 2012; 98: 209-210.

7. Lindsay DS, Dubey JP, Butler JM, Blagburn BL. Mechanical transmission of Toxoplasma gondii oocysts by dogs. Vet Parasitol 1997; 73: 27-33.

8. Tsai YJ, Chung WC, Fei AC, Hong CL, Tsai YY, Peng S, Wu YL. Prevalence of Toxoplasma gondii antibodies in stray dogs in Taipei, Taiwan. J Parasitol 2008; 94: 1437-1437.

9. Machacova T, Bártová E, Sedlák K, Slezáková R, Budíková M, Piantedosi D, Veneziano V. Seroprevalence and risk factors of infections with Neospora caninum and Toxoplasma gondii in hunting dogs from Campania region, southern Italy. Folia Parasitol (Praha), 2016; 63: 2016.

10. Frenkel JK, Lindsay DS, Parker BB, Dobesh M. Dogs as possible mechanical carriers of Toxoplasma, and their fur as a source of infection of young children. Int J Infect Dis 2003; 7: 292-293.

11. Migliore S, La Marca S, Stabile C, Presti VDML, Vitale M. A rare case of acute toxoplasmosis in a stray dog due to infection of $T$. gondii clonal type I: public health concern in urban settings with stray animals? BMC Vet Res 2017; 13: 249.

12. Bahia-Oliveira L, Gomez-Marin J, Shapiro K. Toxoplasma gondii. In Rose JB, Jiménez-Cisneros B eds, Global Water Pathogen Project. East Lansing, USA. Michigan State University, UNESCO. 2017.

13. Tenter AM, Heckeroth AR, Weiss LM. Toxoplasma gondii: from animals to humans. Int J Parasitol 2000; 30: 1217-1258.

14. Yan C, Fu LL, Yue CL, Tang RX, Liu YS, Lv L, Zhou DH. Stray dogs as indicators of Toxoplasma gondii distributed in the envi- 
ronment: the first report across an urban-rural gradient in China. Parasites Vectors 2000; 5: 5.

15. Chandrawathani P, Nurulaini R, Zanin C, Premaalatha B, Adnan M, Jamnah O, Seah TC. Research Note Seroprevalence of Toxoplasma gondii antibodies in pigs, goats, cattle, dogs and cats in peninsular Malaysia. Trop Biomed 2008; 25: 257-258.

16. Fazly ZA, Nurulaini R, Shafarin MS, Fariza N, Zawida Z, Muhamad HY, Adnan M, Premaalatha B, Erwanas AI, Zaini CM, Ong CC, Chandrawathani P. Zoonotic parasites from exotic meat in Malaysia. Trop biomed 2013; 30: 535-542.

17. Puvanesuaran VR, Noordin R, Balakrishnan V. Genotyping of Toxoplasma gondii isolates from wild boars in Peninsular Malaysia. 2013 PLoS One; 8: e61730.

18. Sabri AR, Hassan L, Sharma RSK, Noordin MM. Toxoplasma gondii infection in native village chickens (Gallus domesticus) in Selangor and Melaka, Malaysia. Trop Biomed 2019; 36: 604609.

19. Sahimin N, Lim YAL, Ariffin F, Behnke JM, Basáñez MG, Walker M, Lewis JW, Noordin R, Abdullah KA, Mohd Zain SN. Sociodemographic determinants of Toxoplasma gondii seroprevalence in migrant workers of Peninsular Malaysia. Parasites Vectors 2017; 10: 238.

20. Sukthana Y. Toxoplasmosis: beyond animals to humans. Trends Parasitol 2006; 22: 137-142.

21. Lopes AP, Santos H, Neto F, Rodrigues M, Kwok OCH, Dubey JP, Cardoso L. Prevalence of antibodies to Toxoplasma gondii in dogs from northeastern Portugal. J Parasitol 2011; 97: 418-420.

22. Wu SM, Huang SY, Fu BQ, Liu GY, Chen JX, Chen MX, Yuan ZG, Zhou DH, Weng YB, Zhu XQ, Ye DH. Seroprevalence of T. gondii infection in Lanzhou, Northwest China. Parasite Vectors 2011; 4: 64.

23. Nguyen T, Choe SE, Byun JW, Koh HB, Lee HS, Kang SW. Seroprevalence of Toxoplasma gondii and Neospora caninum in dogs from Korea. Acta Parasitol 2012; 57: 7-12.

24. Costa DGC, Marvulo MFV, Silva JSA, Santana SC, Magalhães FJR, Lima Filho CDF, Ribeiro VO, Alves LC, Mota RA, Dubey JP, Silva JCR. Seroprevalence of Toxoplasma gondii in domestic and wild animals from the Fernando de Noronha, Brazil. J Parasitol 2012; 98: 679-680.

25. Meireles LR, Galisteo Jr AJ, Pompeu E, Andrade Jr HF. Toxoplasma gondii spreading in an urban area evaluated by seroprevalence in free-living cats and dogs. Trop Med Int Health 2004; 9: 876-881.

26. Jiang HH, Li MW, Xu MJ, Cong W, Zhu XQ. Prevalence of Toxoplasma gondii in dogs in Zhanjiang, Southern China. Korean J Parasitol 2015; 53: 493-496.

27. Sedlak K, Bartova E. The prevalence of Toxoplasma gondii IgM and IgG antibodies in dogs and cats from the Czech Republic. Vet Med-Czech 2006; 51: 555.

28. Zhou M, Cao S, Sevinc F, Sevinc M, Ceylan O, Liu M, Nishikawa
Y. Enzyme-linked immunosorbent assays using recombinant TgSAG2 and NcSAG1 to detect Toxoplasma gondii and Neospora caninum-specific antibodies in domestic animals in Turkey. J Vet Med Sci 2016; 78: 1877-1881.

29. Jiang W, Liu Y, Chen Y, Yang Q, Chun P, Yao K, Wang Q. A novel dynamic flow immunochromatographic test (DFICT) using gold nanoparticles for the serological detection of Toxoplasma gondii infection in dogs and cats. Biosens Bioelectron 2015; 72: 133-139.

30. de Paula Dreer MK, Gonçalves DD, da Silva Caetano IC, Gerônimo E, Menegas PH, Bergo D, Ruiz Lopes-Mori FM, Benitez A, de Freitas JC, Evers F, Navarro IT, Martins Lde A. Toxoplasmosis, leptospirosis and brucellosis in stray dogs housed at the shelter in Umuarama municipality, Paraná, Brazil. J Venom Anim and Toxins Incl Trop Dis 2013; 19: 23.

31. Dubey JP, Rajapakse RP, Wijesundera RR, Sundar N, Velmurugan GV, Kwok OC, Su C. Prevalence of Toxoplasma gondii in dogs from Sri Lanka and genetic characterization of the parasite isolates. Vet Parasitol 2007; 146: 341-346.

32. Alvarado-Esquivel C, Romero-Salas D, Cruz-Romero A, GarcíaVázquez Z, Peniche-Cardeña A, Ibarra-Priego N, Ahuja-Aguirre C, Pérez-de-León AA, Dubey JP. High prevalence of Toxoplasma gondii antibodies in dogs in Veracruz, Mexico. BMC Vet Res 2014; 10: 191.

33. Guy LM, Penuliar GM. Seroprevalence and risk factor analysis of Toxoplasma gondii Among Stray and Domesticated Dogs (Canis familiaris) in Antipolo and Metro Manila. Philipp J Sci 2016; 145: 49-55.

34. Zhang XX, Cai YN, Wang CF, Jiang J, Xu YT, Yang GL, Zhao Q. Seroprevalence and risk factors of Toxoplasma gondii infection in stray dogs in northern China. Parasitol Res 2015; 114: 47254729.

35. Fábrega L, Restrepo CM, Torres A, Smith D, Chan P, Pérez D, Cumbrera A, Caballero EZ. Frequency of Toxoplasma gondii and Risk Factors Associated with the Infection in Stray Dogs and Cats of Panama. Microorganisms 2020; 8: 927.

36. Saldanha-Elias AM, Silva MA, Silva VO, Amorim SLA, Coutinho AR, Santos HA, Giunchetti RC, Vitor RWA, Geiger SM. Prevalence of Endoparasites in Urban Stray Dogs from Brazil Diagnosed with Leishmania, with Potential for Human Zoonoses. Acta Parasit 2019; 64: 352-359.

37. Yang N, Mu M, Li H, Hu J, Gao W, Yang S, He J. Seroprevalence of Toxoplasma gondii infection in pet dogs in Shenyang, northeastern China. J Parasitol 2013; 99: 176-177.

38. Gharekhani1 J, Yakhchali M, Abbasi-Doulatshahi E, Barati E. Seroprevalence of Neospora caninum and Toxoplasma gondii Infections in stray dogs of hamadan suburb, West of Iran, 2018. Avicenna J Clin Microbiol Infect 2019; 6: 57-60. 